\title{
RENAL HEMODYNAMICS, SODIUM AND WATER EXCRETION IN SUPINE EXERCISING NORMAL AND CARDIAC PATIENTS ${ }^{1}$
}

\author{
By OSCAR W. FREEMAN, ${ }^{2}$ GEORGE W. MITCHELL, ${ }^{2}$ JOSEPH S. WILSON, F. W. \\ FITZHUGH, AND ARTHUR J. MERRILL WITH THE TECHNICAL ASSISTANCE OF \\ BEVERLY BURNS AND ELOISE CAVIN
}

\author{
(From the Renal and Electrolyte Laboratory, Department of Medicine, Emory University \\ School of Medicine and Grady Memorial Hospital, Atlanta, Ga.)
}

(Submitted for publication December 13, 1954; accepted March 23, 1955)

Diminished sodium excretion is one of the factors underlying edema formation in congestive heart failure. The clinical improvement and disappearance of the edema in some cardiac patients treated with bed rest alone suggests the importance of exercise as a potentiating factor in the sodium retention. Exercise studies carried out in normal and cardiac patients in the upright position by other investigators are open to question since the upright position itself is a factor in diminished sodium excretion. In order to exclude postural effects completely, it became necessary to study renal hemodynamics and electrolyte and water excretion in supine exercising subjects.

The present study reports the effect of exercise in the supine subject on renal plasma flow, glomerular filtration rate, sodium and water excretion. Fifteen control subjects and eleven cardiac patients were studied. The control series consisted of convalescent patients who presented no evidence of cardiovascular or renal disease. All of the cardiac subjects were receiving digitalis preparations. All had received mercurial diuretics, varying from one day to two weeks prior to the study. The cardiac subjects were divided into two groups depending on their clinical appraisal at the time of the study. In the "compensated" group were placed those patients who were ambulatory, able to lie flat and were free of edema. In the "severe" group were placed those patients who were confined to bed because of limited exercise tolerance. This group required more frequent mercurial diuretics and were orthopneic. With one exception, they were edematous at time of the study.

1 This project supported by the National Heart Institute of U. S. Public Health Service, Project No. H-59.

2 Research Fellow in Medicine, American Heart Association.

\section{PROCEDURE}

All patients were in the post absorptive state and at complete bed rest for one hour or more prior to the study and remained recumbent throughout. Each subject was given sodium phenobarbital, $0.12 \mathrm{gm}$. subcutaneously, to allay anxiety. All patients were hydrated orally by the administration of $200 \mathrm{cc}$. water every half hour for one to two hours preceding and during the experiment in order to establish a constant diuresis. Clearance periods were fifteen minutes in duration with two control periods preceding and two recovery periods following the exercise period. Renal plasma flow and filtration rate were determined by clearance methods (Goldring and Chasis [1]). Inulin and sodium para-amino-hippurate were delivered intravenously by means of a constant infusion pump. Urine collections were made through an indwelling catheter, using distilled water and air to insure complete collection. Exercise was accomplished by means of a pedal-resistance type of ergometer set at 10 pounds resistance and attached to the foot of the table. In order to obtain a maximum effort, the subjects were encouraged to pedal as vigorously as possible to the point of exhaustion. A two-minute rest was allowed in the middle of the exercise period to permit the collection of a blood sample. The cardiac subjects required more frequent rest periods because of dyspnea and fatigue. The actual duration of maximal exercise in the control group averaged 8.4 minutes, compared with an average of 8 minutes in the milder cardiac patients and 6.9 minutes in the severe cardiac patients.

Inulin and sodium para-amino-hippurate determinations were done according to the method of Schreiner (2) and Goldring and Chasis (1) and all sodium determinations were made with a Fox internal standard flame photometer.

\section{RESULTS}

Each patient served as his own control and the percentage of change from the average of the control values has been derived for each patient for each period. These values were then averaged for each group (Figures 1-3). Changes in renal hemodynamics of 20 per cent or more were considered to be significant. 
The results are presented in Table I and summarized for the control subjects in Figure 1. In the control group of fifteen normal subjects, only three showed a significant change in glomerular filtration rate during exercise. Of these, two showed an increase of 22 per cent and 30 per cent and one a fall of 25 per cent. In each of these three subjects $\mathrm{Na}^{+}$excretion was also significantly altered and in the same direction as the glomerular filtration rate. Excretion of $\mathrm{Na}^{+}$varied considerably in the group, both during control and exercise periods with no consistent directional trend being detected.

Figure 2 represents the averaged data of the five "compensated" cardiac subjects. In this group there was no consistent change in or correlation between glomerular filtration rate and sodium excretion. There was an unexplained decrease in sodium excretion of 44 per cent in one patient which weighted the average for the group and explains the 19 per cent average fall in the sodium excretion shown here. The most marked drop in glomerular filtration rate of any patient in this group was to only 90 per cent of control value or a 10 per cent decrease.

Figure 3 represents data from six patients with severe congestive heart failure. This group re-

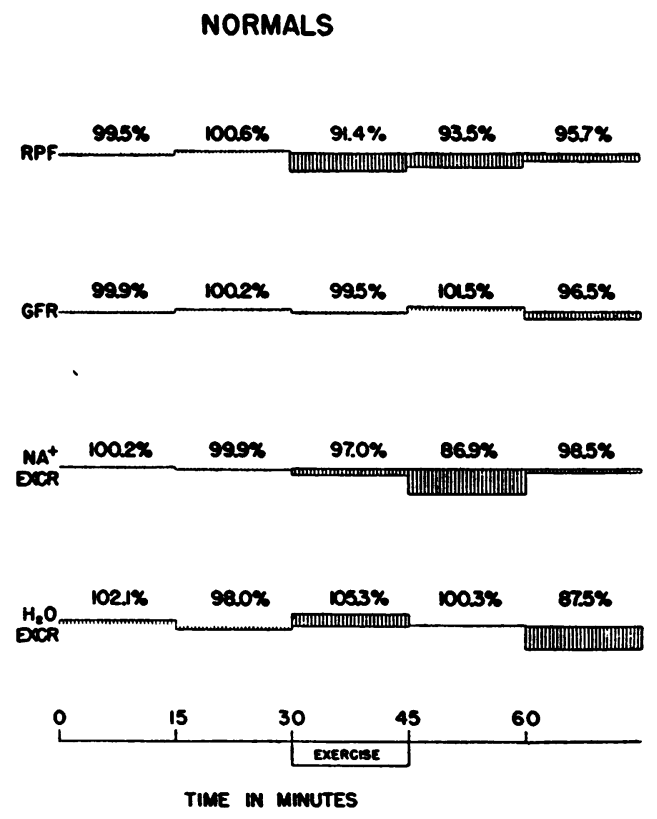

Fig. 1. Averaged Data for Renal Plasma flow, Glomerular Filtration Rate, Sodium and Water Excretion in Fifteen Normal Subjects
COMPENSATED cardoncs
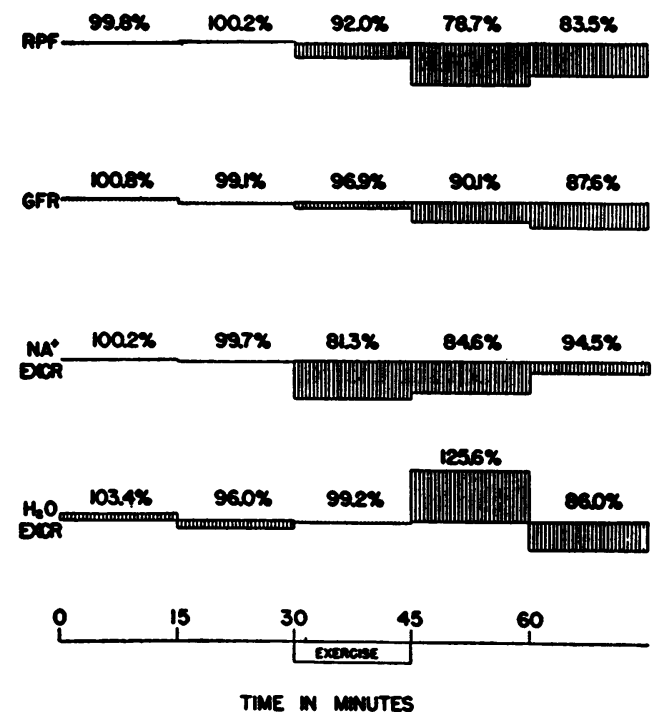

Fig. 2. Averaged Data for Renal Plasma flow, Glomerular Filtration Rate, Sodium and Water Excretion in Five "Compensated" Cardiac PatientsSEE TEXT

\section{SEVERE CARDIACS}

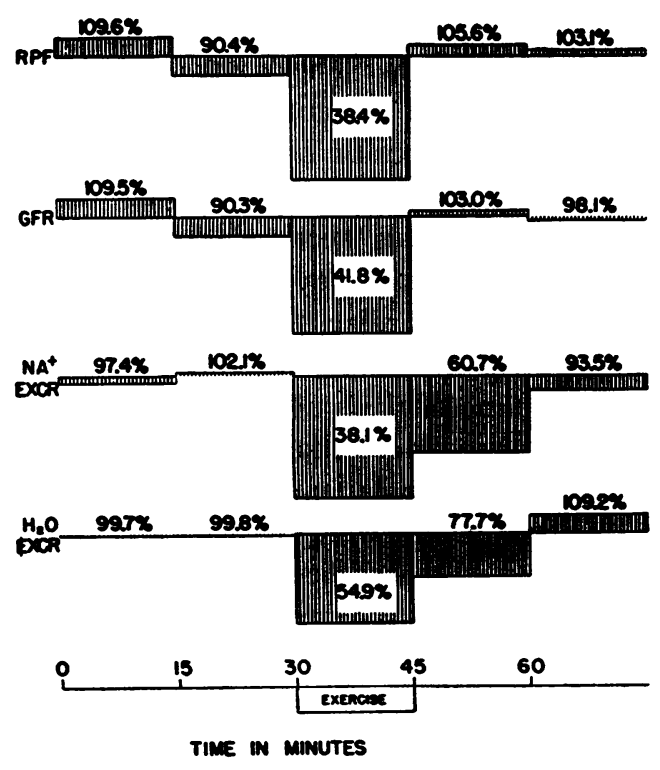

Fig. 3. Averaged Data for Renal Plasma flow, Glomerular Filtration Rate, Sodium and Water Excretton in Six Cardiac Patients with Severe Congestive Heart Failure 
TABLE I

The effect of exercise upon renal function

\begin{tabular}{|c|c|c|c|c|c|c|c|c|c|c|c|c|}
\hline \multirow[b]{2}{*}{ Patient } & \multicolumn{3}{|c|}{$\underset{(c c . / m i n .)}{\mathrm{RPF}}$} & \multicolumn{3}{|c|}{$\underset{(c c . / m i n .)}{\text { GFR }}$} & \multicolumn{3}{|c|}{$\begin{array}{l}\text { Na excretion } \\
(\text { mic } E q . / \text { min.) }\end{array}$} & \multicolumn{3}{|c|}{$\begin{array}{l}\text { Water excretion } \\
(c c . / m i n .)\end{array}$} \\
\hline & Before* & Exercise & After* & Before* & Exercise & After* & Before* & Exercise & After* & Before* & Exercise & After* \\
\hline \multicolumn{13}{|c|}{ Normal } \\
\hline $\begin{array}{l}\text { M. A. } \\
\text { V. A. } \\
\text { N. B. } \\
\text { P. B. } \\
\text { L. G. } \\
\text { J. L. H. } \\
\text { C. L. } \\
\text { M. Mc. } \\
\text { E. N. } \\
\text { J. S. } \\
\text { O. M. S. } \\
\text { H. W. } \\
\text { N. W. } \\
\text { R. W. } \\
\text { S. G. }\end{array}$ & $\begin{array}{l}617 \\
611 \\
617 \\
339 \\
684 \\
546 \\
339 \\
458 \\
702 \\
821 \\
475 \\
596 \\
410 \\
483 \\
406\end{array}$ & $\begin{array}{l}427 \\
474 \\
598 \\
347 \\
579 \\
521 \\
301 \\
445 \\
453 \\
839 \\
467 \\
459 \\
450 \\
584 \\
350\end{array}$ & $\begin{array}{l}617 \\
554 \\
591 \\
369 \\
661 \\
438 \\
348 \\
478 \\
510 \\
731 \\
433 \\
639 \\
362 \\
478 \\
368\end{array}$ & $\begin{array}{r}117 \\
118 \\
105 \\
79 \\
137 \\
110 \\
81 \\
88 \\
135 \\
133 \\
101 \\
131 \\
76 \\
91 \\
106\end{array}$ & $\begin{array}{r}96 \\
117 \\
109 \\
86 \\
140 \\
125 \\
69 \\
81 \\
101 \\
139 \\
101 \\
114 \\
92 \\
118 \\
89\end{array}$ & $\begin{array}{r}100 \\
117 \\
105 \\
90 \\
142 \\
94 \\
80 \\
86 \\
121 \\
135 \\
95 \\
158 \\
76 \\
98 \\
94\end{array}$ & $\begin{array}{r}256 \\
437 \\
88 \\
86 \\
211 \\
171 \\
130 \\
152 \\
238 \\
135 \\
95 \\
169 \\
100 \\
62 \\
136\end{array}$ & $\begin{array}{r}145 \\
421 \\
130 \\
89 \\
163 \\
127 \\
96 \\
119 \\
179 \\
136 \\
98 \\
117 \\
149 \\
75 \\
173\end{array}$ & $\begin{array}{r}193 \\
453 \\
124 \\
95 \\
168 \\
123 \\
108 \\
122 \\
170 \\
150 \\
85 \\
139 \\
105 \\
68 \\
103\end{array}$ & $\begin{array}{r}8.4 \\
13.6 \\
10.4 \\
3.8 \\
9.3 \\
9.2 \\
7.5 \\
6.0 \\
4.5 \\
11.4 \\
8.6 \\
8.7 \\
7.8 \\
2.0 \\
4.4\end{array}$ & $\begin{array}{r}5.9 \\
10.3 \\
10.4 \\
3.7 \\
9.1 \\
10.1 \\
5.7 \\
5.3 \\
5.7 \\
10.1 \\
9.0 \\
6.2 \\
9.1 \\
3.8 \\
7.1\end{array}$ & $\begin{array}{l}6.5 \\
8.3 \\
8.4 \\
5.7 \\
9.3 \\
5.4 \\
6.7 \\
5.6 \\
0.7 \\
8.4 \\
7.7 \\
5.0 \\
7.6 \\
5.2 \\
4.7\end{array}$ \\
\hline \multicolumn{13}{|c|}{ "Compensated" Cardiacs $\dagger$} \\
\hline $\begin{array}{l}\text { C. M. T. } \\
\text { E. B. } \\
\text { F. J. } \\
\text { F. W. } \\
\text { F. T. }\end{array}$ & $\begin{array}{l}329 \\
314 \\
582 \\
246 \\
329\end{array}$ & $\begin{array}{l}347 \\
304 \\
511 \\
199 \\
293\end{array}$ & $\begin{array}{l}260 \\
254 \\
480 \\
179 \\
313\end{array}$ & $\begin{array}{r}76 \\
94 \\
95 \\
115 \\
105\end{array}$ & $\begin{array}{r}82 \\
95 \\
89 \\
106 \\
94\end{array}$ & $\begin{array}{l}64 \\
79 \\
92 \\
98 \\
97\end{array}$ & $\begin{array}{r}113 \\
193 \\
124 \\
72 \\
240\end{array}$ & $\begin{array}{r}111 \\
159 \\
107 \\
40 \\
201\end{array}$ & $\begin{array}{r}82 \\
164 \\
125 \\
49 \\
293\end{array}$ & $\begin{array}{l}6.5 \\
8.2 \\
8.1 \\
2.1 \\
9.0\end{array}$ & $\begin{array}{l}6.5 \\
7.6 \\
4.5 \\
3.4 \\
7.3\end{array}$ & $\begin{array}{l}5.3 \\
5.3 \\
6.1 \\
4.7 \\
7.2\end{array}$ \\
\hline \multicolumn{13}{|c|}{ Severe Cardiacs } \\
\hline $\begin{array}{l}\text { L. P. } \\
\text { J. P. } \\
\text { A. N. } \\
\text { J. G. } \\
\text { J. B. } \\
\text { J. W. W. }\end{array}$ & $\begin{array}{l}257 \\
431 \\
368 \\
272 \\
261 \\
126\end{array}$ & $\begin{array}{r}124 \\
176 \\
179 \\
197 \\
28 \\
12\end{array}$ & $\begin{array}{l}296 \\
367 \\
370 \\
241 \\
171 \\
198\end{array}$ & $\begin{array}{r}108 \\
117 \\
105 \\
89 \\
79 \\
84\end{array}$ & $\begin{array}{l}53 \\
45 \\
56 \\
68 \\
10 \\
18\end{array}$ & $\begin{array}{r}113 \\
112 \\
108 \\
89 \\
68 \\
96\end{array}$ & $\begin{array}{r}68 \\
83 \\
33 \\
369 \\
62 \\
128\end{array}$ & $\begin{array}{r}29 \\
41 \\
11 \\
242 \\
10 \\
29\end{array}$ & $\begin{array}{r}67 \\
80 \\
16 \\
257 \\
36 \\
113\end{array}$ & $\begin{array}{l}.5 \\
7.9 \\
1.3 \\
3.4 \\
5.9 \\
2.9\end{array}$ & $\begin{array}{r}.5 \\
2.4 \\
.6 \\
5.0 \\
.5 \\
.4\end{array}$ & $\begin{array}{r}.8 \\
6.9 \\
1.1 \\
4.3 \\
.6 \\
3.2\end{array}$ \\
\hline
\end{tabular}

* These figures represent the average of two periods. + See text.

vealed very striking and parallel changes. Every patient in this group had a fall in glomerular filtration rate to well below $70 \mathrm{cc}$. per min. during exercise whereas no patient in either of the other groups had falls in glomerular filtration rate of that degree. The profound alterations in renal plasma flow and glomerular filtration rate are accompanied by a corresponding diminution in sodium excretion to an average of 38 per cent of control value or an average fall of 62 per cent. During the recovery periods the sodium excretion tended to lag behind glomerular filtration rate in its return toward control values. This would suggest that in exercise, more than one factor may be involved in diminished sodium excretion. It is also of significance that although this group exercised to the best of their ability the work done was less than that of the group with milder failure. The diminished sodium excretion was not always paralleled by decrease in water excretion since in several patients the water excretion actually increased during exercise while the sodium excretion fell.

\section{DISCUSSION}

In 1943, Eggleton (3) found a decrease in urinary total nitrogen, chloride and water excretion in medical students during short periods of severe exercise. Later Barclay, Cooke, Kenney, and Nutt (4) measured urine volume, total chloride excretion, renal plasma flow, and glomerular filtration rate (using single dose of inulin or mannitol) in normal subjects during a quarter-mile sprint at full speed. All subjects had a decline in renal plasma flow, glomerular filtration rate, urinary $\mathrm{pH}$ and chloride excretion, and there was a fall in urine volume in the majority of subjects. White and Rolf (5) demonstrated decreased re- 
nal plasma flow and glomerular filtration rate and marked increases in renal vascular resistance in normal subjects during periods of exercise. Chapman, Henschel, Minckler, Forsgren, and Keys (6, 7) measured renal plasma flow by the constant infusion method and found significant drops during exercise in normal subjects.

Kattus, Sinclair-Smith, Genest, and Newman (8), and Sinclair-Smith, Kattus, Genest, and Newman (9) found a constant fall in sodium excretion without glomerular filtration rate changes during mild upright exercise in both normal and cardiac subjects. The exercise was carried out in most cases after a long period in the supine position or occasionally after a short period of standing with slight motion. These investigators used endogenous creatinine clearances as the measure of glomerular filtration rate in most cases and voided urine collections were made.

One major objection which may be seen in the above studies is the fact that postural changes may have taken place during the exercise period of the experiments. It is well recognized that there is an appreciable diminution in water and electrolyte excretion when the erect position is assumed. This phenomenon has been demonstrated most conclusively in the tilting experiments of Brun, Knudsen, and Raaschou $(10,11)$. Their data indicate that the anti-diuresis which occurs with tilting to the upright position probably may be explained by a humoral factor such as excessive circulating posterior pituitary secretion. Their patients, however, were motionless and a decrease in circulating blood volume due to venous pooling is likely. Recently, Lewis, Buie, Sevier, and Harrison (12) and Viar, Oliver, Eisenberg, Lombardo, Willis, and Harrison (13) noted that when a subject assumes the sitting position without exercise, there is a significant reduction in sodium excretion with no change in glomerular filtration rate as measured by creatinine clearance. These are the same findings that Kattus reports in his exercised subjects.

In the experiments of Kattus, Sinclair-Smith, Genest, and Newman, an attempt was made to separate the postural effects in some subjects by having short control periods of standing with slight motion. Their exhibition of no change in renal clearance and slight diminutions in sodium excretion is at variance with preliminary studies done in this laboratory. Experiments reported in this communication were done with the subjects supine throughout, thereby completely ruling out postural effects.

The data here reported differ from those of Kattus, Sinclair-Smith, Genest, and Newman in two important particulars: First, the results show no consistent effect of exercise on sodium excretion or glomerular filtration rate in the normal or "compensated" cardiac subjects, where Kattus found a consistent drop in sodium excretion without any change in glomerular filtration rate; secondly, in the decompensated cardiac subjects there was a profound fall in sodium excretion during exercise and this was invariably accompanied by a comparable reduction in glomerular filtration rate. The reasons for the discrepancies are not immediately apparent, but the consistent fall in sodium excretion in Kattus' experiments may be related to assumption of the upright position rather than to exercise per se.

The degree to which alterations in sodium excretion paralleled changes in glomerular filtration during exercise is rather striking in view of the marked variation in sodium excretion in both directions in other periods.

The degree and duration of the urine volume changes with exercise are out of proportion to the changes in renal plasma flow, glomerular filtration rate, and sodium excretion. Water excretion seemed to vary independently of glomerular filtration rate and sodium excretion. Therefore, it seems reasonable to postulate a separate mechanism for the anti-diuresis. Klisiecki, Pickford, Rothschild, and Verney (14) found that the antidiuresis associated with exercise could not be abolished by complete renal denervation. It may be primarily due to increased formation of antidiuretic hormone, with neurogenic and hemodynamic factors playing secondary roles.

\section{SUMMARY}

A study of renal plasma flow, glomerular filtration rate, sodium and water excretion in fifteen normal and eleven cardiac subjects during supine exercise has been presented. There was no consistent change in or correlation of sodium excretion and glomerular filtration rate in the normal subjects or "compensated" cardiac patients during exercise in the supine position. In the more 
severe cardiac patients, renal plasma flow, glomerular filtration rate, and sodium excretion fell significantly in every case during exercise.

It is suggested that the previously reported diminution in $\mathrm{Na}^{+}$excretion in exercising cardiac subjects without concomitant reduction in inulin clearance was a postural effect.

\section{REFERENCES}

1. Goldring, W., and Chasis, H., Hypertension and $\mathbf{H y}-$ pertensive Disease. New York, The Commonwealth Fund, 1944.

2. Schreiner, G. E., Determination of inulin by means of resorcinol. Proc. Soc. Exper. Biol. \& Med., 1950, 74, 117.

3. Eggleton, M. G., The effect of exercise on chloride excretion in man during water diuresis and tea diuresis. J. Physiol., 1943, 102, 140.

4. Barclay, J. A., Cooke, W. T., Kenney, R. A., and Nutt, M. E., The effects of water diuresis and exercise on the volume and composition of urine. Am. J. Physiol., 1947, 148, 327.

5. White, H. L., and Rolf, D., Effects of exercise and of some other influences on the renal circulation in man. Am. J. Physiol., 1948, 152, 505.

6. Chapman, C. B., Henschel, A., Minckler, J., Forsgren, A., and Keys, A., The effect of exercise on renal plasma flow in normal male subjects. J. Clin. Invest., 1948, 27, 639.

7. Chapman, C. B., Henschel, A., and Forsgren, A., Renal plasma flow during moderate exercise of several hours' duration in normal male subjects. Proc. Soc. Exper. Biol. \& Med., 1948, 69, 170.

8. Kattus, A. A., Sinclair-Smith, B., Genest, J., and Newman, E. V., The effect of exercise on the renal mechanism of electrolyte excretion in normal subjects. Bull. Johns Hopkins Hosp., 1949, 84, 344.

9. Sinclair-Smith, B., Kattus, A. A., Genest, J., and Newman, E. V., The renal mechanism of electrolyte excretion and the metabolic balances of electrolytes and nitrogen in congestive heart failure: The effects of exercise, rest and aminophylline. Bull. Johns Hopkins Hosp., 1949, 84, 369.

10. Brun, C., Knudsen, E. O. E., and Raaschou, F., The influence of posture on the kidney function. I. The fall of the diuresis in the erect posture. Acta med. Scandinav., 1945, 122, 315.

11. Brun, C., Knudsen, E. O. E., and Raaschou, F., The influence of posture on the kidney function. II. Glomerular dynamics in the passive erect posture. Acta med. Scandinav., 1945, 122, 332.

12. Lewis, J. M., Jr., Buie, R. M., Sevier, S. M., and Harrison, T. R., The effect of posture and of congestion of the head on sodium excretion in normal subjects. Circulation, 1950, 2, 822.

13. Viar, W. N., Oliver, B. B., Eisenberg, S., Lombardo, T. A., Willis, K., and Harrison, T. R,. The effect of posture and of compression of the neck on excretion of electrolytes and glomerular filtration: Further studies. Circulation, 1951, 3, 105.

14. Klisiecki, A., Pickford, M., Rothschild, P., and Verney, E. B., The absorption and excretion of water by the mammal. II. Factors influencing the response of the kidney to water-ingestion. Proc. Roy. Soc., London, 1933, B112, 521. 